\title{
Routine Assessment of Symptoms of Substance Use Disorders in Primary Care: Prevalence and Severity of Reported Symptoms
}

\author{
Mikko Sayre, BS ${ }^{1,2}$, Gwen T. Lapham, PhD, MPH, MSW' , Amy K. Lee, MPH', \\ Malia Oliver, $B A^{7}$, Jennifer F. Bobb, $P h D^{7}$, Ryan M. Caldeiro, $M D^{7}$, and \\ Katharine A. Bradley, MD, $\mathrm{MPH}^{7}$
}

${ }^{7}$ Kaiser Permanente Washington Health Research Institute, Seattle, WA, USA; ${ }^{2}$ Columbia-Bassett Program at Columbia University College of Physicians and Surgeons, Cooperstown, NY, USA.

BACKGROUND: Most patients with substance use disorders (SUDs) never receive treatment and SUDs are underrecognized in primary care (PC) where patients can be treated or linked to treatment. Asking PC patients to directly report SUD symptoms on questionnaires might help identify SUDs but to our knowledge, this approach is previously untested.

OBJECTIVE: To describe the prevalence and severity of DSM-5 SUD symptoms reported by PC patients as part of routine care.

DESIGN: Cross-sectional study using secondary data.

PARTICIPANTS: A total of 241,265 adult patients who visited one of $25 \mathrm{PC}$ sites in an integrated health system in Washington state and had alcohol, cannabis, or other drug use screening documented in their EHRs (March 2015-July 2018) were included in main analyses if they had a positive screen for high-risk substance use defined as AUDIT-C score 7-12 points, or report of past-year daily cannabis use or any other drug use.

MAIN MEASURES: The main outcome was number of SUD symptoms based on Diagnostic and Statistical Manual, 5th edition (DSM-5), reported on Symptom Checklists (0-11) for alcohol or other drugs: 2-3 mild; 4-5 moderate; $6-11$ severe.

RESULTS: Of screened patients, 16,776 (5.7\%) reported high-risk use of alcohol (2.4\%), cannabis (3.9\%), and/or other drugs (1.7\%), and 65.0-69.9\% of those completed Symptom Checklists. Of those with high-risk alcohol use, $52.5 \%$ (95\% CI 50.9-54.0\%) reported $\geq 2$ symptoms consistent with mild-severe alcohol use disorders. Of those reporting daily cannabis use, $29.8 \%$ (28.6-30.9\%) reported $\geq 2$ symptoms consistent with mild-severe SUDs. Of those reporting any other drug use, 37.5\% (35.7-39.3\%) reported $\geq 2$ symptoms consistent with mild-severe SUDs.

Prior presentations: This paper was presented as a poster at the Dissemination and Implementation Conference, Washington DC, December 2018.

Electronic supplementary material The online version of this article (https://doi.org/10.1007/s11606-020-05650-3) contains supplementary material, which is available to authorized users.

Received February 8, 2019

Revised October 10, 2019

Accepted December 10, 2019

Published online January 23, 2020
CONCLUSIONS AND RELEVANCE: Many PC patients who screened positive for high-risk substance use reported symptoms consistent with DSM-5 SUDs on self-report Symptom Checklists. Use of SUD Symptom Checklists could support PC providers in making SUD diagnoses and initiating discussions of substance use.

KEY WORDS: alcohol; cannabis; drug use; substance use; behavioral health; screening; primary care; addiction; substance use disorders.

J Gen Intern Med 35(4):1111-9

DOI: $10.1007 / \mathrm{s} 11606-020-05650-3$

(C) Society of General Internal Medicine 2020

\section{INTRODUCTION}

An estimated 60.9 million Americans drink above recommended limits, and 27.1 million use other drugs. ${ }^{1}$ With past-year prevalence rates of $13.9 \%$ for alcohol use disorders (AUDs) ${ }^{2}$ and $3.9 \%$ for drug use disorders (DUDs), ${ }^{3}$ substance use disorders (SUDs) account for significant public health burden in terms of morbidity, mortality, and cost. ${ }^{1,4-10}$ Disability and death due to opioid and alcohol use disorders have increased recently. ${ }^{11}$

Without screening, AUDs and other DUDs often remain unrecognized and untreated, ${ }^{3,12}$ despite availability of effective treatments that can be provided in primary care. ${ }^{13-19}$ Efforts to improve identification and treatment of SUDs in primary care often start with brief screening questionnaires, ${ }^{20-}$ 28 followed by a second screen for AUDs or other DUDs. ${ }^{29-32}$ However, such an approach still requires the clinician to make a diagnosis before patients can be offered treatment (e.g., medications for AUD or opioid use disorders). An alternative approach $^{33}$ recommended recently ${ }^{34}$ is to use Diagnostic and Statistical Manual of Mental Disorders (DSM) ${ }^{35}$ criteria to identify and assess the severity of SUDs. ${ }^{36,37}$ However, little is known about how often patients with unhealthy substance use would report DSM symptoms of SUDs when results will be documented in their electronic health record (EHRs).

The aim of this study was to describe the prevalence and severity of symptoms of SUDs reported on Symptom Checklists by primary care patients who screened positive for highrisk substance use as part of routine care documented in the 
EHR. A secondary aim was to describe the association between the quantity and/or frequency of alcohol or other drug use reported on brief screening questionnaires and the severity of reported SUD symptoms (mild, moderate, or severe).

\section{METHODS}

\section{Study Setting, Design, Sample, and Data Sources}

Annual behavioral health screening, followed by routine assessment of high-risk alcohol or other drug use, was implemented as part of Behavioral Health Integration in all 25 primary care clinics of Kaiser Permanente Washington, a large health system in the Pacific Northwest, ${ }^{38,} 39$ between March 3, 2015, and July 31, 2018. Implementation was staggered with 2-4 primary care clinics launching behavioral health screening every 4 months, as part of the randomized stepped-wedge pragmatic Sustained Patient-centered Alcohol-related Care (SPARC) trial. ${ }^{38,39}$ After screening was launched at each clinic, adult primary care patients $\geq 18$ years were asked to complete a 7-item annual paper screen for depression, alcohol, cannabis, and other drug use (eFigure 1, online). The screen consisted of the two-item Patient Health Questionnaire (PHQ2) for depression, ${ }^{40}$ the Alcohol Use Disorders Identification Test-Consumption (AUDIT-C) for alcohol, ${ }^{28,}, 41,42$ and two single-item screens for the frequency of past-year cannabis and other drug use. ${ }^{23,43}$ The screen was given to patients at check-in or by medical assistants (MAs) before their appointment and entered into the EHR by MAs as part of routine care. If a patient screened positive for high-risk alcohol or other drug use (defined below), the EHR prompted MAs to give them an Alcohol and/or Substance Use Symptom Checklist, a paper questionnaire which included eleven questions for DSM-5 AUD or other DUD symptoms. MAs entered results of the Symptom Checklist(s) into EHRs, usually before patients were seen by their primary care providers.

This cross-sectional study relied entirely on secondary data obtained from the Kaiser Permanente Washington's EHR and insurance claims. Adult patients were included if they had an in-person visit with a primary care provider at a Kaiser Permanente Washington clinic after behavioral health screening was implemented (Fig. 1).] $\rightarrow$

The study received a waiver of informed consent and HIPAA authorization from the Kaiser Permanente Washington Health Research Institute Institutional Review Board.

\section{Measures}

Alcohol, Cannabis, and Other Drug Screenings. The AUDIT-C is a three-item screen that asks about frequency and quantity of typical past-year drinking $(0-4$ points each question), validated in diverse primary care populations. ${ }^{24,} 28$, $41,42,44-46$ AUDIT-C scores range $0-12$ points and sexspecific screening thresholds validated for unhealthy alcohol use are $\geq 3$ for women and $\geq 4$ for men. For descriptive purposes, AUDIT-C scores were categorized as 0, 1-2 female/1-3 male, 3-4 female/4 male, 5-6, 7-8, and 9-12 in this study. Frequency of past-year cannabis use was assessed, regardless of purpose (e.g., medical or non-medical use), with a single-item that asked about cannabis use: "How often in the past year have you used marijuana?" using response options from AUDIT-C question no. 3: never $=0$, less than monthly = 1 , monthly $=2$, weekly $=3$, daily or almost daily $=4$ (eFigure 1, online). ${ }^{43,}{ }^{47}$ Frequency of past-year other drug use was also assessed with a single-item with the same response options, "How often in the past year have you used an illegal drug (not marijuana) or used a prescription medication for non-medical reasons?" adapted from a validated screen (eFigure 1, online) ${ }^{23,43,47}$ Each patient's first complete screen documented in the EHR was used.

High-Risk Alcohol, Cannabis, and Other Drug Use. Patients were considered to screen positive for high-risk substance use ("high-risk use" hereafter) if they had AUDIT-C scores 7-12, reported daily cannabis (score 4), or any other drug use (scores 1-4). These cutoffs for high-risk substance use were chosen because of the following: alcohol consumption increases markedly above AUDIT-C scores of 7 along with symptoms of AUDs; ${ }^{46}$ the risk of cannabis use disorder (CUD) is highest among people who use daily; ${ }^{48,} 49$ and other drugs (e.g., opioids, stimulants) have high addictive potential with any use. ${ }^{50}$

\section{DSM-5 Symptoms of SUDs Reported on Symptom} Checklists. When primary care patients screened positive for high-risk alcohol and/or other substance use, an EHR prompt indicated the patient was to receive a paper-based Symptom Checklist for alcohol and/or other substance use (eFigures 23, online). The Alcohol Symptom Checklist has 11 questions (yes/no) based on DSM-5 AUD criteria, ${ }^{35}$ the Substance Use Symptom Checklist has 11 questions (yes/no) based on DSM5 criteria for non-alcohol SUDs. For both Symptom Checklists, the number of endorsed symptoms $(0-11)$ was categorized as $0,1,2-3,4-5$, and 6 or more symptoms, consistent with DSM-5 criteria for mild (2-3 symptoms), moderate (4, $5)$, and severe (6 or more) SUDs. Symptom Checklists were considered complete if documented in the EHR with at least two questions answered. The first Symptom Checklist in the EHR on the day of the visit or in the following year of a corresponding positive screen for high-risk substance use was included in analyses.

\section{Other Measures}

Demographic characteristics as well as other behavioral health screen results (PHQ-2 and any documentation of past-year tobacco use) were obtained from the EHR. The PHQ-2 includes two questions each scored $0-3$ and was considered positive for depression if either question was scored 2 or 3 (eFigure 1, online). ${ }^{51}$ Past-year diagnoses of mental health disorders and SUDs, based on International Classification of 


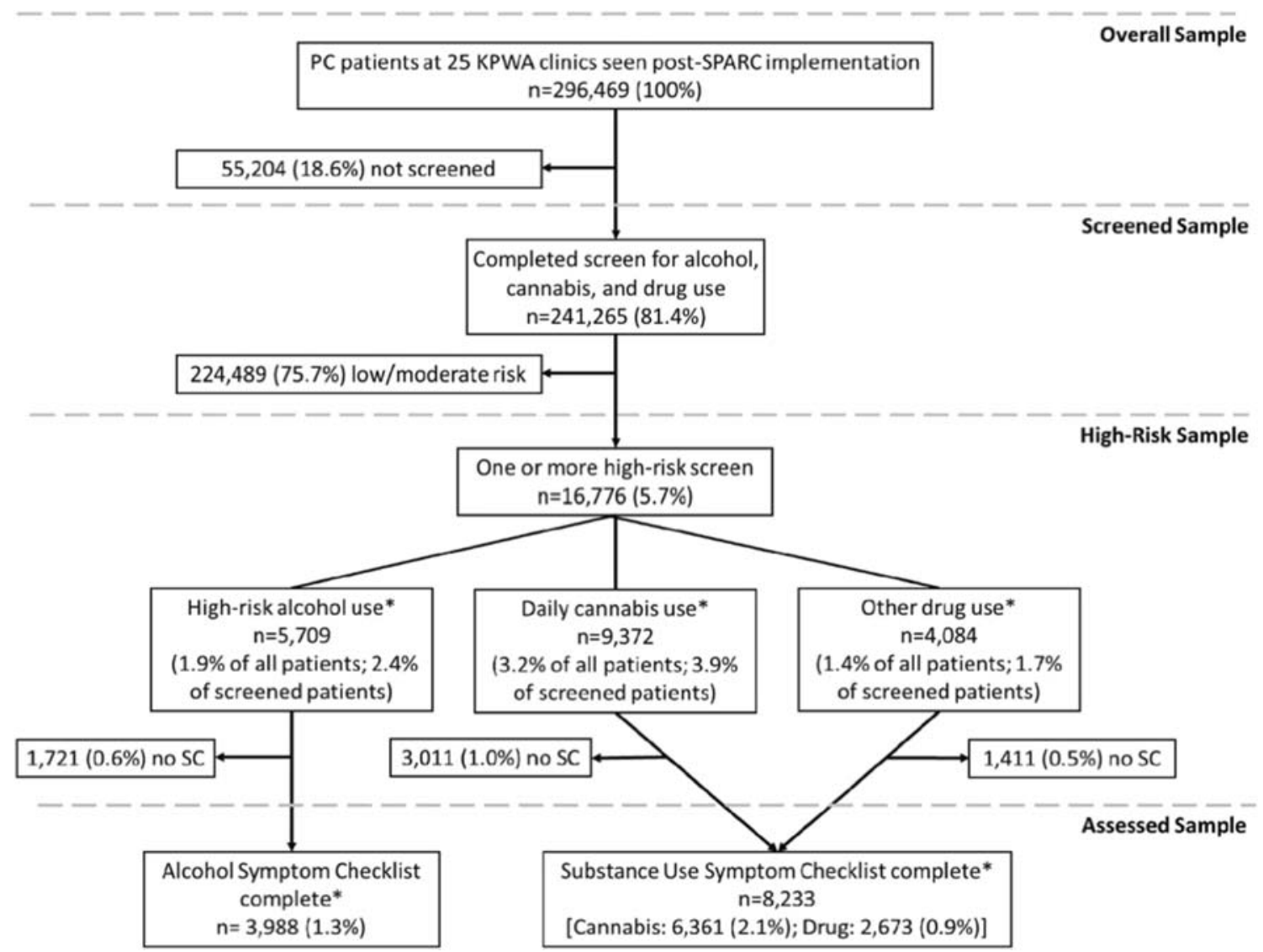

Fig. 1 Study sample. Percentages indicate proportion of total primary care patients seen during the study period, except where indicated. *Overlapping sample, not mutually exclusive (see Fig. 2). SC $=$ Symptom Checklist. High-risk alcohol use $=$ AUDIT-C score 7-12 points.

Disease (ICD) 9th and 10th edition, were obtained from the EHR and insurance claims in the year prior to the screen date. Mental health disorder diagnoses included past-year depression (including major depression and dysthymia), anxiety (including panic, phobias, post-traumatic stress-disorder, and other anxiety disorders), and serious mental illness (including bipolar disorder and schizophrenia). AUD, CUD, and other DUDs (opioid, cocaine, hallucinogen, sedative/hypnotic/anxiolytic, inhalant, other stimulants, and other psychoactive SUDs) were defined by ICD codes used for widely used quality metrics. $^{52}$

\section{Analyses}

All analyses were conducted at the patient level. The prevalence of substance use screening among patients who visited primary care, as well as the characteristics of screened patients, and those with any high-risk use, was described. The prevalence and overlap of high-risk alcohol, cannabis, and other drug use among patients with any high-risk use were estimated. Secondary analyses compared screened patients with and without documented high-risk use, using chi-square tests of independence.

The prevalence (95\% confidence intervals [CIs]) of symptoms of DSM-5 SUDs reported on Symptom Checklists, and symptoms consistent with SUDs, is described among those with high-risk use who completed the Checklists. Additionally, among these same patients, the association was assessed between screening scores for alcohol and other drug use and (1) the mean number of DSM-5 AUD or DUD symptoms; (2) the percent of patients with at least 2 DSM-5 AUD or DUD symptoms; and (3) the prevalence of symptoms consistent with mild, moderate, and severe AUDs or DUDs. Finally, the prevalence of each individual patient-reported AUD or DUD symptom was described. To examine possible bias in the sample who completed Symptom Checklists, secondary analyses compared patients with high-risk use who completed Symptom Checklists to those who did not, using chi-square tests of independence.

Stata MP Version 15.0 software was used for all analyses.

\section{RESULTS}

\section{Demographic, Screening, and Behavioral Health Characteristics}

During the study period, 241,265 (81.4\% of eligible primary care patients) completed screening for alcohol, cannabis, and other drug use (Fig. 1). Among screened patients, 2.4\% (2.3$2.4 \%)$ reported high-risk alcohol use, $3.9 \%(3.8-4.0 \%)$ daily cannabis use, and $1.7 \%(1.6-1.7 \%)$ any other drug use. 
Table 1 Demographic, Screening, and Clinical Characteristics of the Sample of Primary Care Patients Who Completed Screening, and Those with Screens Indicating High-Risk Alcohol, Cannabis, and/or Other Drug Use

\begin{tabular}{|c|c|c|c|c|}
\hline & \multicolumn{2}{|c|}{$\begin{array}{l}\text { All screened } \\
\text { patients } \\
(n=241,265)\end{array}$} & \multicolumn{2}{|c|}{$\begin{array}{l}\text { High-risk } \\
\text { screens } \\
(n=16,776)\end{array}$} \\
\hline & $n$ & $(\%)$ & $n$ & $(\%)$ \\
\hline \multicolumn{5}{|l|}{ Age } \\
\hline $18-29$ & 36,090 & $(15.0)$ & 5200 & $(31.0)$ \\
\hline $30-49$ & 71,610 & $(29.7)$ & 6059 & $(36.1)$ \\
\hline $50-64$ & 93,800 & (38.9) & 4770 & $(28.4)$ \\
\hline $65+$ & 39,700 & $(16.5)$ & 736 & (4.4) \\
\hline \multicolumn{5}{|l|}{ Sex } \\
\hline Female & 142,611 & $(59.1)$ & 6717 & $(40.0)$ \\
\hline Male & 98,654 & $(40.9)$ & 10,059 & $(60.0)$ \\
\hline Hispanic or Latino & 13,516 & $(5.6)$ & 1100 & $(6.6)$ \\
\hline \multicolumn{5}{|l|}{ Race } \\
\hline Asian & 23,897 & $(9.9)$ & 659 & (3.9) \\
\hline Black & 11,661 & $(4.8)$ & 940 & $(5.6)$ \\
\hline Hawaiian/Pacific Islander & 2234 & $(0.9)$ & 169 & $(1.0)$ \\
\hline Multiracial & 6255 & $(2.6)$ & 658 & (3.9) \\
\hline $\begin{array}{l}\text { Native American/Alaska Na- } \\
\text { tive }\end{array}$ & 1753 & $(0.7)$ & 159 & $(0.9)$ \\
\hline Other/unknown & 18,676 & (7.7) & 1577 & $(9.4)$ \\
\hline White & 176,789 & (73.3) & 12,614 & $(75.2)$ \\
\hline Past-year tobacco use & 24,293 & $(10.1)$ & 4924 & $(29.4)$ \\
\hline \multicolumn{5}{|l|}{ AUDIT-C score } \\
\hline 0 & 68,569 & $(28.4)$ & 1720 & $(10.3)$ \\
\hline $1-2$ women/1-3 men & 105,615 & $(43.8)$ & 4586 & $(27.3)$ \\
\hline 3-4 women/4 men & 45,030 & (18.7) & 2617 & $(15.6)$ \\
\hline $5-6$ & 16,342 & $(6.8)$ & 2144 & $(12.8)$ \\
\hline $7-8$ & 4063 & (1.7) & 4063 & $(24.2)$ \\
\hline $9-12$ & 1646 & $(0.7)$ & 1646 & $(9.8)$ \\
\hline \multicolumn{5}{|l|}{ Cannabis use screen score } \\
\hline 0 (never) & 195,189 & $(80.9)$ & 3532 & $(21.1)$ \\
\hline 1 (less than monthly) & 21,893 & $(9.1)$ & 1965 & $(11.7)$ \\
\hline 2 (monthly) & 6988 & (2.9) & 828 & (4.9) \\
\hline 3 (weekly) & 7823 & (3.2) & 1079 & (6.4) \\
\hline 4 (daily) & 9372 & (3.9) & 9372 & $(55.9)$ \\
\hline \multicolumn{5}{|l|}{ Drug use screen score } \\
\hline 0 (never) & 237,181 & $(98.3)$ & 12,692 & $(75.7)$ \\
\hline 1 (less than monthly) & 3060 & (1.3) & 3060 & $(18.2)$ \\
\hline 2 (monthly) & 426 & $(0.2)$ & 426 & $(2.5)$ \\
\hline 3 (weekly) & 222 & $(0.1)$ & 222 & (1.3) \\
\hline 4 (daily) & 376 & $(0.2)$ & 376 & $(2.2)$ \\
\hline \multicolumn{5}{|l|}{ PHQ-2 depression screen } \\
\hline Positive & 32,680 & $(13.5)$ & 2994 & $(17.8)$ \\
\hline \multicolumn{5}{|l|}{ Past-year mental health diagnoses } \\
\hline Depression & 41,823 & $(17.3)$ & 4288 & $(25.6)$ \\
\hline Anxiety & 31,209 & (12.9) & 3492 & $(20.8)$ \\
\hline Serious mental illness & 3158 & $(1.3)$ & 461 & $(2.7)$ \\
\hline \multicolumn{5}{|c|}{ Past-year substance use disorder diagnoses } \\
\hline Any SUD (except tobacco) & 7480 & $(3.1)$ & 3438 & $(20.5)$ \\
\hline Alcohol use disorder & 4326 & (1.8) & 1991 & $(11.9)$ \\
\hline Cannabis use disorder & 1778 & $(0.7)$ & 1229 & $(7.3)$ \\
\hline $\begin{array}{l}\text { Non-cannabis drug use } \\
\text { disorder }\end{array}$ & 2161 & $(0.9)$ & 681 & $(4.1)$ \\
\hline
\end{tabular}

Percentages may not add to 100 due to missing or unreported data. Past-year mental health and substance use diagnoses based on ICD-9 and ICD-10 codes in the year prior to screening (see "METHODS")

Table 1 shows characteristics of the screened population and the 16,776 patients with screening indicating high-risk use- $6.9 \%$ (95\% CI $6.9-7.0 \%)$ of those screened. Of those patients with any high-risk use, $13.0 \%(12.5-13.5 \%)$ reported high-risk use of more than one substance (Fig. 2). Patients with high-risk alcohol, cannabis, or other drug use differed from those without (eTable 1). Compared with patients without, patients with high-risk alcohol, cannabis, or other drug use were also considerably more likely than those without to have a documented past-year diagnosis of AUD, CUD, and DUD: $29.0 \%$ versus $1.0 \%, 11.5 \%$ versus $0.2 \%$, and $13.7 \%$ versus $0.6 \%$, respectively ( $p$ value 0.001 ; eTable 1$).]->$

\section{Prevalence of Reported SUD Symptoms on Symptom Checklists}

Overall, 65.0-69.9\% of eligible patients completed Symptom Checklists (Fig. 1). Alcohol Symptom Checklists were completed by 3988 (69.9\%; 68.7-71.0\%) of eligible patients, and Substance Use Symptom Checklists were completed by 6361 $(67.9 \% ; 66.9-68.8 \%)$ of patients with daily cannabis use and 2673 (65.4\%; 63.9-66.8\%) of those reporting any other drug use. The magnitude of differences between eligible patients who did and did not complete Symptom Checklists was generally small (eTable 2).

Among patients with high-risk alcohol use who completed Alcohol Symptom Checklists, 52.5\% (50.9-54.0\%) reported $\geq 2$ symptoms consistent with a DSM-5 AUD (Table 2). Of patients with daily cannabis use who completed a Substance Use Symptom Checklist, 29.8\% (28.6-30.9\%) reported $\geq 2$ SUD symptoms (Table 2). Among patients with any other drug use who completed a Substance Use Symptom Checklist, $37.5 \%(35.7-39.3 \%)$ reported $\geq 2$ SUD symptoms.

\section{Association Between Screening Scores and DSM-5 Symptoms}

Among patients with high-risk alcohol or other noncannabis drug use who completed the respective Alcohol or Substance Use Symptom Checklists, there was a strong association between screen scores and the prevalence and number of reported AUD or SUD symptoms (Fig. 3; eTable 3 ). The prevalence of $\geq 2$ symptoms of AUD increased from $40.5 \%(38.2-42.8 \%)$ for patients with AUDIT-C scores of 7 to $91.4 \%$ (85.3-95.1\%) for those with scores of 12 . For patients who used other drugs, the prevalence of $\geq 2$ SUD symptoms increased from $26.6 \%$ (24.7-28.7\%) for patients reporting less than monthly other drug use to $79.0 \%(73.7-83.5 \%)$ for those reporting daily or almost daily use. Similarly, the prevalence of 6 or more symptoms-consistent with severe AUD or SUD - increased markedly across the range of high-risk screen scores: from $8.2(7.0-9.6 \%)$ to $77.7 \%$ (69.9$83.9 \%)$ for alcohol and $7.3(6.2-8.5 \%)$ to $62.5 \%(56.5-$ $68.2 \%$ ) for other drugs (Fig. 3). The mean number of AUD symptoms reported increased from 1.8 (1.7-1.9) with AUDIT-C score of 7 to 7.7 (7.1-8.3) with AUDIT-C score of 12 (eTable 3 ). For SUD symptoms, the mean number of symptoms increased from $1.3(1.3-1.4)$ for those reporting less than monthly use of other drugs (score of 1 ) to 6.6 (6.1-7.1) for those with daily use (score of 4).] $\rightarrow$

The most commonly reported DSM-5 symptoms of AUD or other SUDs on the Symptom Checklists varied somewhat 


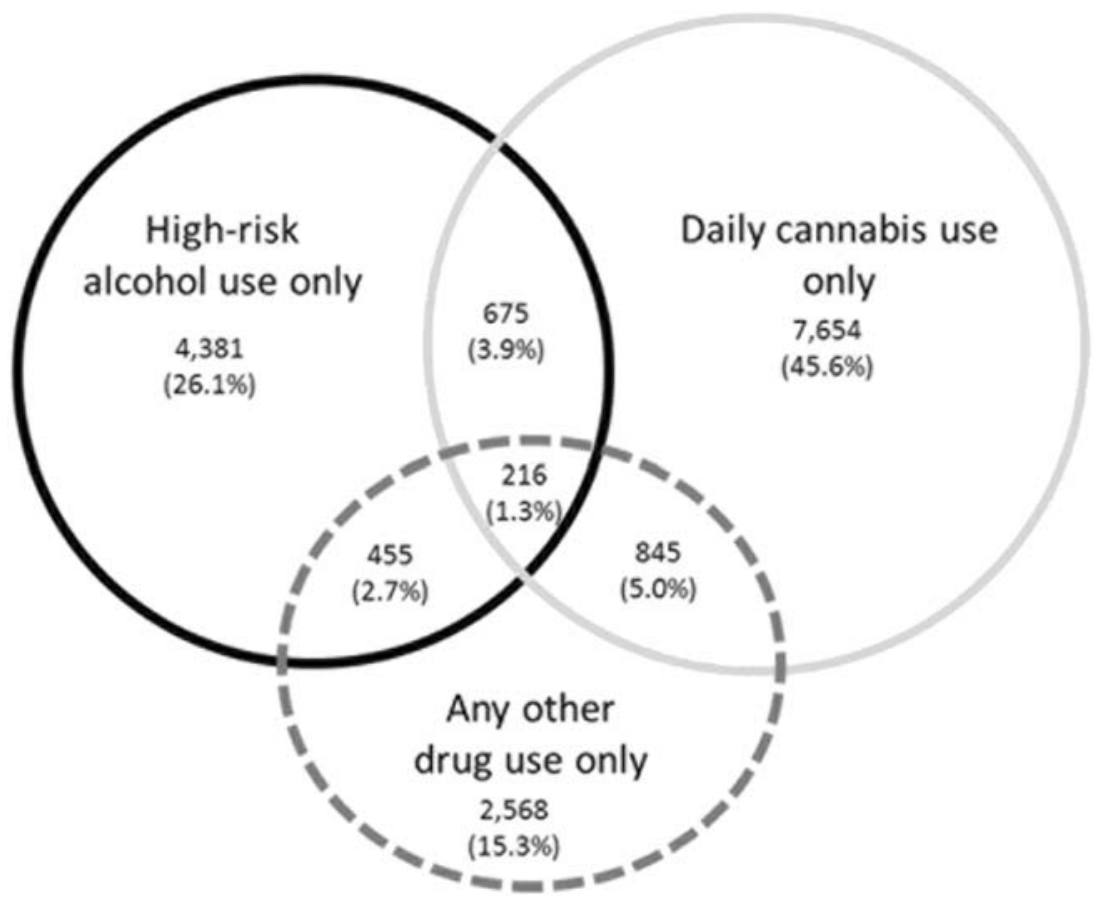

Fig. 2 Overlap between high-risk alcohol, cannabis, and other drug use. Of 16,776 patients with high-risk use of alcohol, cannabis, or other drugs (5709 reporting high-risk alcohol use, 9372 reporting high-risk cannabis use, 4084 reporting high-risk use of other drugs), 2173 reported high-risk use of more than one substance. Area of circles is proportional to the sample size.

for those with high-risk alcohol, cannabis, or other drug use. However, continued use despite knowing it was causing mental or physical problems and report of strong desires or cravings to use were common in all 3 groups (eFigure 4, online).

\section{DISCUSSION}

This study evaluated patient-reported symptoms of SUD documented in EHRs as part of routine primary care for patients who reported high-risk substance use. Results show that over

Table 2 Prevalence of AUD or SUD Symptoms Among Those Who Screened High-Risk and Completed Symptom Checklists

\begin{tabular}{|c|c|c|c|}
\hline & \multicolumn{3}{|c|}{$\begin{array}{c}\text { Alcohol Symptom Checklist } \\
\text { High-risk alcohol use }(n=3988)\end{array}$} \\
\hline DSM-5 AUD symptoms & $\%$ & & $(95 \% \mathrm{CI})$ \\
\hline None & 30.1 & & $(28.7-31.6)$ \\
\hline 1 & 17.4 & & $(16.2-18.6)$ \\
\hline 2-3 (mild) & 21.3 & & $(20.0-22.6)$ \\
\hline 4-5 (moderate) & 12.0 & & $(11.1-13.1)$ \\
\hline 6 or more (severe) & 19.2 & & $(18.0-20.4)$ \\
\hline \multirow[t]{2}{*}{ Consistent with mild-severe DSM-5 AUD* } & 52.5 & & $(50.9-54.0)$ \\
\hline & \multicolumn{3}{|c|}{$\begin{array}{l}\text { Substance Use Symptom Checklist } \\
\text { Daily cannabis use }(n=6361)\end{array}$} \\
\hline DSM-5 SUD symptoms & $\%$ & & $(95 \% \mathrm{CI})$ \\
\hline None & 49.9 & & $(48.7-51.1)$ \\
\hline 1 & 20.4 & & $(19.4-21.4)$ \\
\hline $2-3$ (mild) & 17.9 & & $(17.0-18.8)$ \\
\hline 4-5 (moderate) & 6.4 & & $(5.8-7.0)$ \\
\hline 6 or more (severe) & 5.5 & & $(5.0-6.1)$ \\
\hline Consistent with mild-severe DSM-5 CUD* & 29.8 & & $(28.6-30.9)$ \\
\hline & & Any other drug use $(n=2670)$ & \\
\hline DSM-5 SUD symptoms & $\%$ & & $(95 \% \mathrm{CI})$ \\
\hline None & 48.5 & & $(46.6-50.4)$ \\
\hline 1 & 14.0 & & $(12.7-15.3)$ \\
\hline 2-3 (mild) & 14.5 & & $(13.1-15.8)$ \\
\hline 4-5 (moderate) & 6.7 & & $(5.8-7.8)$ \\
\hline 6 or more (severe) & 16.3 & & $(15.0-17.8)$ \\
\hline Consistent with mild-severe DSM-5 DUD* & 37.5 & & $(35.7-39.3)$ \\
\hline
\end{tabular}

High-risk alcohol use = AUDIT-C score 7-12 points

*Note that the Symptom Checklist did not assess whether symptoms were recurrent and - for the SUD Symptoms Checklist-whether symptoms were due to cannabis and/or other drugs. Therefore, a diagnosis of AUD, CUD, or DUD required assessment by a clinician 


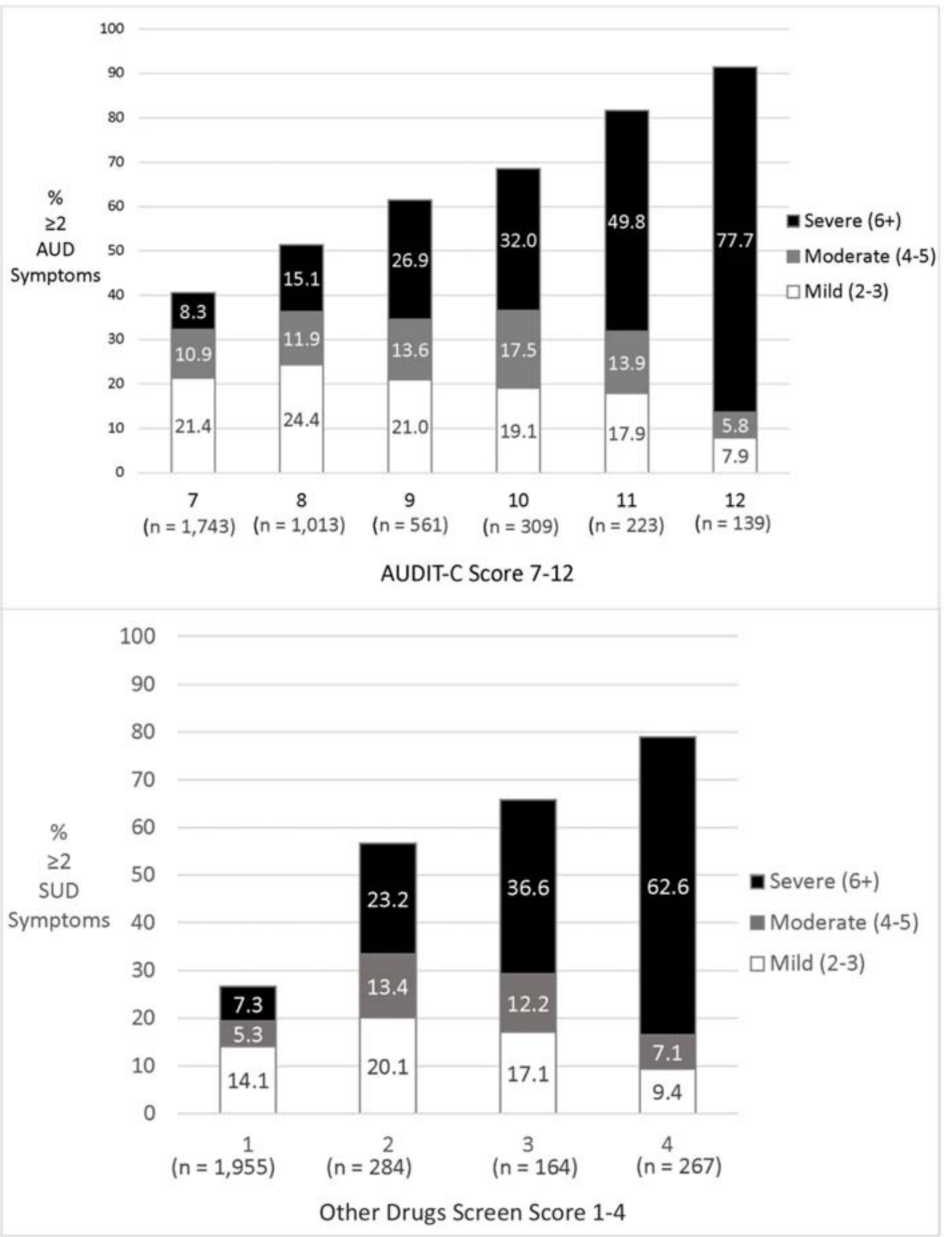

Fig. 3 Proportion of patients with at least 2 AUD or DUD symptoms across high-risk alcohol and other (non-cannabis) drug screening scores. The number of symptoms from the Alcohol Symptom Checklist is shown across AUDIT-C scores 7-12 (top), and the number of symptoms from the Substance Use Checklist is shown across any other drug screen score (bottom). Combined bar height indicates proportion of sample with 2 or more AUD or DUD symptoms. $(n=)$ indicates number of patients at each screening score who completed the Symptom Checklist.

half of patients with high-risk alcohol use reported $\geq 2$ DSM-5 symptoms of AUD, consistent with at least mild AUD, whereas $30 \%$ and $38 \%$ of those with high-risk cannabis or other drug use, respectively, reported $\geq 2$ DSM-5 DUD symptoms. Moreover, the higher the screening scores, the greater the prevalence and number of DSM-5 symptoms.

No prior study to our knowledge has reported the prevalence and severity of DSM- 5 symptoms of AUD or SUD among primary care patients who screen positive for highrisk substance use. Findings are consistent with prior research regarding the AUDIT-C in the National Epidemiologic Survey of Alcohol and Related Conditions (NESARC), ${ }^{46}$ but the mean number of AUD symptoms at any given AUDIT-C score was higher in the present study's clinical sample. At the highest alcohol and other drug screen scores, $78 \%$ and $63 \%$ respectively reported $\geq 6$ DSM-5 symptoms consistent with severe SUDs. Results suggest that often SUDs were not previously recognized by patients' providers. Among patients with high-risk alcohol, cannabis, or other drug use who completed Symptom Checklists, the prevalence of AUD, CUD, or DUD diagnoses documented in the past year was $32 \%, 12 \%$, and $16 \%$, respectively (eTable 2), while the prevalence of 2 or more patient-reported DSM-5 symptoms was $53 \%, 30 \%$, and $38 \%$, respectively (Table 2). Primary care patients who screen positive for unhealthy alcohol or substance use fall on a spectrum: some have asymptomatic unhealthy use of alcohol, cannabis, and other drugs, while others have mild to severe symptoms of AUD or other SUDs. The former might benefit 
from brief preventive counseling - shown to decrease drinking in patients with unhealthy alcohol use $\mathrm{u}^{20,21}$ - whereas those with AUD or other DUDs benefit from treatment. ${ }^{14-17}$, 19 Therefore, identification of AUDs and DUDs among those who screen positive on brief substance use screening questionnaires may be a crucial step towards improving treatment of SUDs. $^{12,30,31,53-55}$ However, no consensus exists about the optimal approach to identifying those with AUD and DUD among the much larger group of patients with unhealthy substance use. Previously recommended approaches for identifying SUDs include secondary screens, ranging from 2 to 10 items for alcohol. ${ }^{29-32}$ Even if secondary screens suggest SUDs, primary care providers may want a definitive diagnosis before offering treatment. ${ }^{14,56,57}$ While some health systems use a telephonic Behavioral Health Lab to diagnose SUDs, ${ }^{16}$ most patients are not referred and those who are referred for assessment often do not accept referral to subsequent specialty treatment, ${ }^{16,58}$ consistent with limitations in the reach of referral generally. ${ }^{59-61}$

In contrast, this study showed that integration of routine DSM-5 Symptom Checklists into primary care resulted in high rates of assessment, with many patients reporting symptoms consistent with DSM-5 SUDs. This simplified the process for primary care providers to make a diagnosis: once patients completed the questions on paper and MAs had entered DSM symptoms into the EHR, providers only needed to confirm the symptoms and their recurrence to make a diagnosis. Moreover, providers could enter the exam room knowing whether they were going to offer preventive counseling or explore AUD symptoms and offer shared decision-making ${ }^{62}$ and treatment. ${ }^{14,56,57}$ Providers could then treat AUDs or opioid use disorders with medications, and/or offer "warm handoffs" to social workers or other integrated behavioral health clinicians for further motivational interviewing, shared decision-making, or evidence-based counseling, as appropriate. Future research will evaluate whether this process increases diagnosis and treatment of SUDs.

Use of DSM Symptom Checklists for SUDs provides another important advantage in primary care: supporting patientcentered discussions of alcohol and other substance use and associated symptoms, and thereby potentially helping to destigmatize SUDs and their treatment. The Symptom Checklist can make it easier for primary care providers to initiate comfortable conversations about a stigmatized topic in a nonjudgmental manner. A provider can refer to the Symptom Checklist and say, "You indicated that you suspected your alcohol use may cause or worsen mental or physical problems. Can you tell me more about that?" While some symptoms like tolerance may not bother patients, other symptoms like "wanted to or tried to cut back or stop... but have been unable" indicate patients may be open to shared decision-making about treatment options. Patients' symptoms could then be monitored over time. ${ }^{34}$

This study had several limitations. First, under-reporting of substance use and DSM-5 symptoms of SUDs is expected due to stigma. However, despite this, we found that many patients reported substance use and SUD symptoms, and self-report on paper screens and Symptom Checklists may minimize social desirability bias. ${ }^{63}$ Moreover, more AUD symptoms were reported at a given AUDIT-C score than in a study using detailed, confidential interviews, ${ }^{46}$ potentially reflecting differences in populations or a greater tendency of patients to report high-risk substance use when they are having symptoms. Another limitation was that the single items for cannabis and drug use and the Symptom Checklists (eFigures 1-3, online) have not been validated. However, these screens were based on validated questions, ${ }^{23,31,64}$ and other validated DSM diagnostic instruments for SUDs have used a single item for each DSM criterion. ${ }^{58,65}$ Also, Symptom Checklists were not documented in the EHR for all primary care patients with high-risk use, and there was variation in Symptom Checklist completion across age and sex (eTable 2). It is not known whether this is due to patient refusal, lack of time, or primary care staff discomfort. Some anecdotes suggested MAs were uncomfortable assessing substance use in certain patients (e.g., older patients). Finally, the Kaiser Permanente Washington primary care population may not reflect other primary care populations, especially uninsured patients.

For many individuals with SUDs, primary care may be their only health care contact, ${ }^{12,66,67}$ placing primary care providers in a prime position to identify, assess, and treat SUDs. ${ }^{16}$, 68, 69 A coordinated and systematic approach using a brief paper-based screen for substance use, followed by Symptom Checklists for those with high-risk use, offers a patientcentered approach to identifying and engaging patients. This study showed that such an approach is feasible and that many patients reported 2 or more symptoms on the DSM-5 Symptom Checklists, with increasing severity of SUDs as screen scores increased.

Acknowledgments: The authors would like to acknowledge the important contributions of KP Washington leaders, clinicians, and patients, and all SPARC trial co-investigators and team members, who participated in implementation of routine screening and assessment for substance use in KP Washington primary care clinics. We also appreciate Ms. Erica Hilario for her assistance preparing the manuscript.

Corresponding Author: Mikko Sayre, BS; Columbia-Bassett Program at Columbia University College of Physicians and Surgeons, Cooperstown, NY, USA (e-mail: mns2144@cumc.columbia.edu).

Funding Information This project was supported by the grant number R18HSO23173 from the Agency for Healthcare Research and Quality. Research reported in this publication was supported by the National Institute On Alcohol Abuse And Alcoholism of the National Institutes of Health under Award Number K24AA022128. Funding was also provided by the Columbia-Bassett Program at Columbia University College of Physicians and Surgeons.

\section{Compliance with Ethical Standards:}

Conflict of Interest: The authors declare that they do not have a conflict of interest. 
Disclaimer: The content is solely the responsibility of the authors and does not necessarily represent the official views of the Agency for Healthcare Research and Quality and the National Institutes of Health. The funding sponsors had no role in the design of the study; in the collection, analyses, or interpretation of data; in the writing of the manuscript; and in the decision to publish the results.

\section{REFERENCES}

1. Substance Abuse and Mental Health Services Administration Center for Behavioral Health Statistics and Quality. Behavioral health trends in the United States: results from the 2014 National Survey on Drug Use and Health. Rockville, MD: Substance Abuse and Mental Health Services Administration;2015.

2. Grant BF, Goldstein RB, Saha TD, et al. Epidemiology of DSM-5 alcohol use disorder: results from the National Epidemiologic Survey on Alcohol and Related Conditions III. JAMA Psychiatry. 2015;72(8):757-766.

3. Grant BF, Saha TD, Ruan WJ, et al. Epidemiology of DSM-5 drug use disorder: results from the National Epidemiologic Survey on Alcohol and Related Conditions-III. JAMA Psychiatry. 2016;73(1):39-47.

4. Seth P, Scholl L, Rudd RA, Bacon S. Overdose deaths involving opioids, cocaine, and psychostimulants - United States, 2015-2016. MMWR Morb Mortal Wkly Rep. 2018;67(12):349-358.

5. Hasin DS, Grant BF. The National Epidemiologic Survey on Alcohol and Related Conditions (NESARC) waves 1 and 2: review and summary of findings. Soc Psychiatry Psychiatr Epidemiol. 2015;50(11):1609-1640.

6. Blanco C, Iza M, Rodriguez-Fernandez JM, Baca-Garcia E, Wang S, Olfson M. Probability and predictors of treatment-seeking for substance use disorders in the U.S. Drug Alcohol Depend. 2015;149:136-144.

7. Hasin DS, Stinson FS, Ogburn E, Grant BF. Prevalence, correlates, disability, and comorbidity of DSM-IV alcohol abuse and dependence in the United States: results from the National Epidemiologic Survey on Alcohol and Related Conditions. Arch Gen Psychiatry. 2007;64(7):830 842 .

8. Kessler RC, Berglund P, Demler O, Jin R, Merikangas KR, Walters EE. Lifetime prevalence and age-of-onset distributions of DSM-IV disorders in the National Comorbidity Survey Replication. Arch Gen Psychiatry. 2005;62(6):593-602.

9. Timko C, Kong C, Vittorio L, Cucciare MA. Screening and brief intervention for unhealthy substance use in patients with chronic medical conditions: a systematic review. J Clin Nurs. 2016;25(2122):3131-3143.

10. World Health Organization. Global Strategy to Reduce the Harmful Use of Alcohol. Geneva, Switzerland: World Health Organization;2010.

11. Collaborators TUSBoD. The state of us health, 1990-2016: burden of diseases, injuries, and risk factors among us states. JAMA. 2018;319(14):1444-1472.

12. Tai B, Wu LT, Clark HW. Electronic health records: essential tools in integrating substance abuse treatment with primary care. Subst Abuse Rehabil. 2012;3:1-8.

13. Marsden J, Tai B, Ali R, Hu L, Rush AJ, Volkow N. Measurementbased care using DSM-5 for opioid use disorder: can we make opioid medication treatment more effective? Addiction. 2019. PMCID: PMC6766896

14. Jonas DE, Amick HR, Feltner C, et al. Pharmacotherapy for adults with alcohol use disorders in outpatient settings: a systematic review and meta-analysis. JAMA. 2014;311(18): 1889-1900.

15. Fiellin DA, O'Connor PG. Clinical practice. Office-based treatment of opioid-dependent patients. N Engl J Med. 2002;347(11):817-823.

16. Oslin DW, Lynch KG, Maisto SA, et al. A randomized clinical trial of alcohol care management delivered in Department of Veterans Affairs primary care clinics versus specialty addiction treatment. $J$ Gen Intern Med. 2014;29(1):162-168.

17. Alford DP, LaBelle CT, Kretsch N, et al. Collaborative care of opioidaddicted patients in primary care using buprenorphine: five-year experience. Arch Intern Med. 2011;171(5):425-431.

18. LaBelle CT, Han SC, Bergeron A, Samet JH. Office-Based Opioid Treatment with Buprenorphine (OBOT-B): statewide implementation of the Massachusetts collaborative care model in community health centers. $J$ Subst Abuse Treat. 2016;60:6-13.

19. Watkins KE, Ober AJ, Lamp K, et al. Collaborative care for opioid and alcohol use disorders in primary care: the SUMMIT randomized clinical trial. JAMA Intern Med. 2017; 177(10):1480.
20. O'Connor EA, Perdue LA, Senger CA, et al. Screening and behavioral counseling interventions to reduce unhealthy alcohol use in adolescents and adults: updated evidence report and systematic review for the us preventive services task force. JAMA. 2018;320(18):1910-1928.

21. U. S. Preventive Services Task Force, Curry SJ, Krist AH, et al. Screening and behavioral counseling interventions to reduce unhealthy alcohol use in adolescents and adults: US Preventive Services Task Force Recommendation Statement. JAMA. 2018;320(18): 1899-1909.

22. Smith PC, Schmidt SM, Allensworth-Davies D, Saitz R. Primary care validation of a single-question alcohol screening test. $J$ Gen Intern Med. 2009;24(7):783-788.

23. Smith PC, Schmidt SM, Allensworth-Davies D, Saitz R. A singlequestion screening test for drug use in primary care. Arch Intern Med. 2010;170(13):1155-1160.

24. Johnson JA, Lee A, Vinson D, Seale JP. Use of AUDIT-based measures to identify unhealthy alcohol use and alcohol dependence in primary care: a validation study. Alcohol Clin Exp Res. 2013;37 Suppl 1:E253259.

25. McNeely J, Cleland CM, Strauss SM, Palamar JJ, Rotrosen J, Saitz R. Validation of Self-Administered Single-Item Screening Questions (SISQs) for unhealthy alcohol and drug use in primary care patients. J Gen Intern Med. 2015;30(12):1757-1764.

26. McNeely J, Strauss SM, Saitz R, et al. A brief patient self-administered substance use screening tool for primary care: two-site validation study of the Substance Use Brief Screen (SUBS). Am J Med. 2015;128(7):784 e789-719.

27. McNeely J, Wu LT, Subramaniam G, et al. Performance of the Tobacco, Alcohol, Prescription Medication, and other Substance use (TAPS) tool for substance use screening in primary care patients. Ann Intern Med. 2016; 165(10):690-699.

28. Bradley KA, DeBenedetti AF, Volk RJ, Williams EC, Frank D, Kivlahan DR. AUDIT-C as a brief screen for alcohol misuse in primary care. Alcohol Clin Exp Res. 2007;31(7):1208-1217.

29. National Institute on Alcohol Abuse and Alcoholism. Helping Patients Who Drink Too Much: A Clinician's Guide (Updated 2005 Edition). Washington, D.C.: National Institutes of Health, U.S. Department of Health and Human Services;2005. NIH Publication 07-3769.

30. Vinson DC, Kruse RL, Seale JP. Simplifying alcohol assessment: two questions to identify alcohol use disorders. Alcohol Clin Exp Res. 2007;31(8): 1392-1398.

31. Humeniuk R, Ali R, Babor TF, et al. Validation of the Alcohol, Smoking and Substance Involvement Screening Test (ASSIST). Addiction. 2008; 103(6): 1039-1047.

32. Yudko E, Lozhkina O, Fouts A. A comprehensive review of the psychometric properties of the Drug Abuse Screening Test. $J$ Subst Abuse Treat. 2007;32(2):189-198.

33. Buchsbaum DG, Buchanan RG, Lawton MJ, Elswick RK, Jr., Schnoll SH. A program of screening and prompting improves short-term physician counseling of dependent and nondependent harmful drinkers. Arch Intern Med. 1993;153(13):1573-1577.

34. National Council for Behavioral Health. Implementing Care for Alcohol \& Other Drug Use in Medical Setting: An Extension of SBIRT. Washington DC: National Council for Behavioral Health; February 2018.

35. Hasin DS, O'Brien CP, Auriacombe M, et al. DSM-5 criteria for substance use disorders: recommendations and rationale. Am J Psychiatry. 2013;170(8):834-851.

36. Dawson DA, Saha TD, Grant BF. A multidimensional assessment of the validity and utility of alcohol use disorder severity as determined by item response theory models. Drug and Alcohol Dependence. 2010;107(1):3138.

37. Dawson DA, Grant BF. Should symptom frequency be factored into scalar measures of alcohol use disorder severity? Addiction. 2010; 105(9): 1568-1579.

38. Bobb JF, Lee AK, Lapham GT, et al. Evaluation of a pilot implementation to integrate alcohol-related care within primary care. Int $J$ Environ Res Public Health. 2017;14(9).

39. Glass JE, Bobb JF, Lee AK, et al. Study protocol: a cluster-randomized trial implementing Sustained Patient-centered Alcohol-related Care (SPARC trial). Implement Sci. 2018;13(1):108.

40. Whooley MA, Avins AL, Miranda J, Browner wS. Case finding instruments for depression. Two questions are as good as many. $J$ Gen Intern Med. 1997;12(7):439-445. 
41. Bush K, Kivlahan DR, McDonell MB, Fihn SD, Bradley KA. The AUDIT alcohol consumption questions (AUDIT-C): an effective brief screening test for problem drinking. Ambulatory Care Quality Improvement Project (ACQUIP). Alcohol Use Disorders Identification Test. Arch Intern Med. 1998; 158(16):1789-1795.

42. Bradley KA, Bush KR, Epler AJ, et al. Two brief alcohol-screening tests from the Alcohol Use Disorders Identification Test (AUDIT): validation in a female Veterans Affairs patient population. Arch Intern Med. 2003; 163(7):821-829.

43. Lapham GT, Lee AK, Caldeiro RM, et al. Frequency of cannabis use among primary care patients in Washington state. J Am Board Fam Med. 2017;30(6):795-805.

44. Dawson DA, Grant BF, Stinson FS, Zhou Y. Effectiveness of the derived Alcohol Use Disorders Identification Test (AUDIT-C) in screening for alcohol use disorders and risk drinking in the US general population. Alcohol Clin Exp Res. 2005;29(5):844-854

45. Frank D, DeBenedetti AF, Volk RJ, Williams EC, Kivlahan DR, Bradley KA. Effectiveness of the AUDIT-C as a screening test for alcohol misuse in three race/ethnic groups. J Gen Intern Med. 2008;23(6):781787.

46. Rubinsky AD, Dawson DA, Williams EC, Kivlahan DR, Bradley KA AUDIT-C scores as a scaled marker of mean daily drinking, alcohol use disorder severity, and probability of alcohol dependence in a U.S. general population sample of drinkers. Alcohol Clin Exp Res. 2013;37(8):13801390.

47. Lapham GT, Lee AK, Caldeiro RM, et al. Prevalence of behavioral health conditions across frequency of cannabis use among adult primary care patients in Washington state. J Gen Intern Med. 2018

48. Hasin DS, Saha TD, Kerridge BT, et al. Prevalence of marijuana use disorders in the United States between 2001-2002 and 2012-2013. JAMA Psychiatry. 2015;72(12):1235-1242.

49. Hasin DS, Kerridge BT, Saha TD, et al. Prevalence and correlates of DSM-5 cannabis use disorder, 2012-2013: findings from the National Epidemiologic Survey on Alcohol and Related Conditions-III. Am J Psychiatry. 2016;173(6):588-599.

50. Compton WM, Thomas YF, Stinson FS, Grant BF. Prevalence, correlates, disability, and comorbidity of DSM-IV drug abuse and dependence in the United States: results from the national epidemiologic survey on alcohol and related conditions. Arch Gen Psychiatry. 2007;64(5):566-576.

51. Kroenke K, Spitzer RL, Williams JB. The Patient Health Questionnaire2: validity of a two-item depression screener. Med Care 2003;41(11):1284-1292.

52. National Committee for Quality Assurance. HEDIS 2018. Washington, DC: National Committee for Quality Assurance;2018.

53. Ghitza UE, Gore-Langton RE, Lindblad R, Shide D, Subramaniam G, Tai B. Common data elements for substance use disorders in electronic health records: the NIDA Clinical Trials Network experience. Addiction. 2013;108(1):3-8.

54. Saitz R, Cheng DM, Allensworth-Davies D, Winter MR, Smith PC. The ability of single screening questions for unhealthy alcohol and other drug use to identify substance dependence in primary care. $J$ Stud Alcohol Drugs. 2014;75(1):153-157
55. Babor TE, Higgins-Biddle J, Dauser D, Higgins P, Burleson JA. Alcohol screening and brief intervention in primary care settings: implementation models and predictors. J Stud Alcohol. 2005;66(3):361-368.

56. Dunlap B, Cifu AS. Clinical management of opioid use disorder. JAMA 2016;316(3):338-339.

57. Kranzler HR, Soyka M. Diagnosis and Pharmacotherapy of Alcohol Use Disorder: a Review. JAMA. 2018;320(8):815-824.

58. Maust DT, Mavandadi S, Klaus J, Oslin DW. Missed opportunities: fewer service referrals after positive alcohol misuse screens in VA primary care. Psychiatr Serv. 2011;62(3):310-312.

59. Glass JE. Challenges ahead in developing and testing referral to treatment interventions. Addiction. 2015;110(9):1419-1420.

60. Glass JE, Hamilton AM, Powell BJ, Perron BE, Brown RT, Ilgen MA Specialty substance use disorder services following brief alcohol intervention: a meta-analysis of randomized controlled trials. Addiction. 2015;110(9):1404-1415

61. Glass JE, Hamilton AM, Powell BJ, Perron BE, Brown RT, Ilgen MA Revisiting our review of Screening, Brief Intervention and Referral to Treatment (SBIRT): meta-analytical results still point to no efficacy in increasing the use of substance use disorder services. Addiction. 2016;111(1): 181-183.

62. Bradley KA, Kivlahan DR. Bringing patient-centered care to patients with alcohol use disorders. JAMA. 2014;311(18):1861-1862.

63. Bradley KA, Lapham GT, Hawkins EJ, et al. Quality concerns with routine alcohol screening in VA clinical settings. $J$ Gen Intern Med. 2011;26(3):299-306

64. Babor TF, Higgins-Biddle JC, Saunders JB, Monteiro MG. AUDIT: The Alcohol Use Disorders Identification Test: Guidelines for Use in Primary Care, 2nd Edition. 2001; https://apps.who.int/iris/bitstream/handle/ $10665 / 67205 /$ W H O M S D M S B 01.6 a . p d f ; jsessionid=06D498C7FA8F53E8C2C1127CE84C74DE?sequence $=1$.

65. Sheehan DV, Lecrubier Y, Sheehan KH, et al. The Mini-International Neuropsychiatric Interview (M.I.N.I.): the development and validation of a structured diagnostic psychiatric interview for DSM-IV and ICD-10. J Clin Psychiatry. 1998;59 Suppl 20:22-33;quiz 34-57.

66. Institute of Medicine (US) Committee on Crossing the Quality Chasm: Adaptation to Mental Health and Addictive Disorders. Improving the Quality of Health Care for Mental and Substance-Use Conditions: Quality Chasm Series. Washington, DC: National Academies Press; 2006.

67. McNeely J, Strauss SM, Wright S, et al. Test-retest reliability of a selfadministered Alcohol, Smoking and Substance Involvement Screening Test (ASSIST) in primary care patients. Journal of substance abuse treatment. 2014;47(1):93-101.

68. Rehm J, Anderson P, Manthey $\mathbf{J}$, et al. Alcohol use disorders in primary health care: what do we know and where do we go? Alcohol Alcohol 2016;51(4):422-427.

69. McQuade WH, Levy SM, Yanek LR, Davis SW, Liepman MR. Detecting symptoms of alcohol abuse in primary care settings. Arch Fam Med. 2000;9(9):814-821.

Publisher's Note Springer Nature remains neutral with regard to jurisdictional claims in published maps and institutional affiliations. 